OPEN ACCESS

Edited by:

Donatella Puglisi,

Linköping University, Sweden

Reviewed by:

Jan Mitrovics,

Independent Researcher,

Tübingen, Germany

Gemma García Mandayo,

Centro de Estudios e Investigaciones

Técnicas de Gipuzkoa, Spain

*Correspondence:

Andreas Schütze

schuetze@/mt.uni-saarland.de

tThese authors have contributed equally to this work and share first authorship

Specialty section: This article was submitted to Sensor Devices,

a section of the journa

Frontiers in Sensors

Received: 24 January 2021 Accepted: 10 March 2021

Published: 01 April 2021

Citation:

Höfner S and Schütze A (2021) Air Quality Measurements and Education: Improving Environmental Awareness

of High School Students.

Front. Sens. 2:657920

doi: 10.3389/fsens.2021.657920

\section{Air Quality Measurements and Education: Improving Environmental Awareness of High School Students}

\author{
Sebastian Höfner ${ }^{\dagger}$ and Andreas Schütze ${ }^{* \dagger}$ \\ Laboratory for Measurement Technology, Saarland University, Saarbrücken, Germany
}

Indoor air quality (IAQ) has gained renewed importance in public awareness, especially in times of the corona pandemic. In classrooms in particular, regular ventilation is essential to keep the potential viral load in the air as low as possible and thus reduce the likelihood of infection with the corona virus. But also the concentration of other pollutants, such as particulate matter (PM) or volatile organic compounds (VOCs), which are responsible for symptoms such as concentration disorders, headaches and dizziness can be reduced. In addition to the direct measurement of VOC pollutants using metal oxide semiconductor (MOS) gas sensors, $\mathrm{CO}_{2}$ is also measured as an indicator gas for monitoring IAQ. However, young people in particular have only a diffuse idea of air pollutants. This can be explained by the fact that many of these air pollutants are both odorless and colorless and are only detectable using suitable sensors. In order to provide students with a comprehensive picture of the topic of air quality and thus strengthen their environmental awareness, declarative, conceptual and procedural knowledge needs to be combined. This includes knowledge about different sensor principles, pollutant types, their limits, health effects on humans and strategies to maintain good air quality, both indoors and outdoors. To ensure that this knowledge does not remain inert, authentic learning scenarios with a direct relevance to everyday life must be provided. Measuring pollutants in indoor air in particular offers the opportunity to apply what has been learned in a context-oriented manner. By linking the performance of measurements with sensors and the subsequent interpretation of measurement results, environmental awareness can be sharpened with regard to IAQ. This can be achieved by measuring pollutants with sensors and then interpreting and classifying the measurement results. In this paper, various student experiments with gas sensors are presented that introduce the function principles of different sensor types, record air quality data and provide meaningful interpretation. Based on these experiences, students are encouraged to develop their own research questions on air quality.

Keywords: air quality, high school students, education, environmental awareness, air pollution 


\section{INTRODUCTION}

The environmental awareness for air pollution is still not very distinct in the general population and especially young people often have only a diffuse and abstract idea of air pollutants. This can be explained by the fact that many air pollutants are both odorless and colorless. Furthermore, the human nose cannot perceive a slow increase in the concentration of odorous pollutants indoors. The health consequences of bad indoor air quality (IAQ) range from fatigue to concentration problems (Chen et al., 2017) and headaches (Wolkoff et al., 2004) to sick building syndrome (US Environmental Protection Agency, 1991). In schools and classrooms, good IAQ is important in order to create optimal conditions for learning. In addition to avoiding high-emission everyday products, regular ventilation is the most effective way to ensure good IAQ. However, due to low outside temperatures in winter, ventilation is not frequent enough, in part because there is often a lack of objective feedback on air quality. One way to obtain immediate and objective feedback is to monitor indoor air via gas sensors. Their use can ensure that objective limit values are maintained above which ventilation becomes necessary.

To actively involve students in the process of maintaining good IAQ and to create acceptance for ventilation measures, the development of environmental awareness about pollutants and air quality is a basic requirement. According to modern concepts of environmental education, this includes environmental knowledge as well as aspects of environmental attitude and environmental behavior (de Haan and Kuckartz, 1996). It has been shown that the mere teaching of environmental knowledge in the form of information about pollutants and sensor principles is a basic prerequisite, but this alone is not sufficient to generate a change in environmental behavior (Szagun et al., 1994; Milton et al., 1995; Rode, 2001). Among other things, this can be attributed to the principle of "inert knowledge" (Renkl et al., 1996). The term refers to the deficient application of knowledge to complex or everyday situations. Accordingly, it is not sufficient to teach only factual knowledge about pollutants. For knowledge not to remain inert, it must be acquired in an active and problem-oriented manner and it needs to be taught in a way that is situated and related to everyday life. Situated learning describes the linking of learning and application processes, e.g., in the form of experiments (de Witt and Czerwionka, 2012), which creates a direct contextual reference (Bahr, 2013).

In addition, environmental knowledge itself can be categorized into declarative, conceptual, and procedural knowledge (Renkl et al., 1996). Declarative knowledge includes both pure factual knowledge, such as knowledge about the existence of pollutants, limit values, and health consequences for humans, as well as knowledge about complex correlations, such as sources of pollutants or underlying measurement principles. According to Anderson, conceptual knowledge is characterized by relationality (Anderson, 1996). This refers to the fact that knowledge about air quality can be abstracted and transferred to similar (everyday) situations. It is therefore the basis for substantive understanding (Schneider, 2006). The term procedural knowledge is defined as knowledge of action. It describes a system of rules for action (procedures) and forms the basis for how what is learned can be implemented in concrete terms in practice. This includes, e.g., strategies for maintaining good air quality, such as regular ventilation or the use of low-emission everyday products with an ecolabel, such as the "Blue Angel."

In the following, various aspects of environmental knowledge related to IAQ-specifically air pollutants and sensor principles-are discussed. Next, experiments are presented that deal with the measurement of various pollutants, as well as the interpretation of measurement results. On this basis, students will be encouraged to develop their own questions and studies related to air quality, thus applying what they have learned in an explicit way. One example of this is the development of a $\mathrm{CO}_{2}$ traffic light in schools.

\section{ENVIRONMENTAL KNOWLEDGE RELATED TO AIR QUALITY}

In 2019, about 400,000 premature deaths in the European Union could be directly attributed to air pollution (European Environment Agency, 2019). However, health consequences of increased exposure to air pollutants often manifest years later, which is why young people in particular do not have intuitive access to the topic of air quality. Therefore, in the first step, it is crucial to provide declarative and conceptual knowledge about the existence of pollutants, their sources, limit values, health effects on humans, and main measurement principles for objective quantification of pollutants. The next step is to abstract what has been learned and apply it to the personal environment. This includes strategies for maintaining good IAQ and is part of the procedural knowledge.

The most common pollutants include volatile organic compounds (VOCs) and particulate matter (PM). Furthermore, indoor $\mathrm{CO}_{2}$ concentration can serve as an indicator of air quality, as it correlates with VOC concentration if humans are the primary source of pollutants through respiration. Different sensor principles are used to detect these pollutants. MOS gas sensors are used to measure VOCs. The measurement of $\mathrm{CO}_{2}$ is based on infrared absorption and particulate matter can be measured using the principle of light scattering.

\section{Volatile Organic Compounds (VOCs)}

VOCs are carbonaceous (organic) substances that evaporate even at low temperatures. According to the World Health Organization (WHO), these substances can be classified into four subcategories depending on their boiling point (BP) (World Health Organization, 2000):

1) Very volatile organic compounds (VVOC; BP: $<5$ to $50-$ $100^{\circ} \mathrm{C}$ )

2) Volatile organic compounds (VOC, BP: $50-100$ to $240-$ $\left.260^{\circ} \mathrm{C}\right)$

3) Semivolatile organic compounds (SVOC, BP: 240-260 to 380$\left.400^{\circ} \mathrm{C}\right)$

4) Particulate organic matter (POM, BP: $>380^{\circ} \mathrm{C}$ ). 
Examples of VOCs are various (aromatic) hydrocarbons (e.g., benzene), aldehydes (e.g., formaldehyde) and alcohols (e.g., isopropanol).

\section{Sources, Limits, and Health Effects}

Due to their chemical properties, VOCs are often used in industry as solvents, adhesives, plasticizers, and fragrances, which means that they are also contained in everyday objects such as furniture, paints, and toys (Guenther et al., 1995). As a result, they are also released into indoor air and can reach the human organism, e.g., through respiration. However, humans themselves also generate VOCs due to their metabolism, leading to an accumulation of VOCs in indoor spaces if ventilation is insufficient.

Different limit values apply depending on the substance. According to the $\mathrm{WHO}$, e.g., there is no safe exposure limit for the carcinogenic benzene, which is why its concentration should be kept as low as possible (World Health Organization, 2010). Formaldehyde has a workplace exposure limit of $0.3 \mathrm{ppm}$, and toluene of $50 \mathrm{ppm}$ (Bundesanstalt für Arbeitsschutz und Arbeitsmedizin, 2006). Due to the large number of different substances, the sum of VOCs is often given as total VOC (TVOC) value for the evaluation of IAQ. Besides $\mathrm{CO}_{2}$, this is now considered a standard indicator for determining IAQ, although this also repeatedly meets with criticism. For example, the different hazard potentials of different VOCs are not considered, which is why the informative value of the effect on health is limited and should only serve as a reference point for more detailed investigations (Sagunski and Heinzow, 2003).

The harmful health effects of VOCs on humans range from impairment of the nervous system, such as impaired concentration and fatigue, to the formation of allergies, asthma, and cancer. In addition, they are associated with sick building syndrome, which causes eye and nose irritation, headaches, and dizziness, among other symptoms (US Environmental Protection Agency, 1991; Wolkoff et al., 2004; Chen et al., 2017).

\section{Simplified Sensor Principle}

MOS gas sensors are often used to detect VOCs. Their function principle is based on the change of their electrical conductivity in the presence of a reducing or oxidizing gas. The theoretical description of the operation of MOS gas sensors is complex and the subject of current research. In order not to overwhelm students, it is therefore useful to convey only the basic principles of the sensor reaction using a simplified model, which is presented in the following. For a detailed description of the model, refer to Höfner et al. (2021).

Figure 1 shows the schematic structure of the simplified sensor model. Electrons, represented by gray dots, move according to the Drude model (Drude, 1900) due to a constant electric voltage $U_{0}$ as free charge carriers within the sensor material. Their directional motion in the $x$-direction is indicated by arrows, with the arrow length proportional to their effective velocity. Above the sensor is the surrounding atmosphere, where oxygen is indicated by blue dots and reducing gas molecules by purple dots. An amperemeter is used to measure the current or electrical current and therefore the conductance. This is proportional to the number and effective velocity of the free charge carriers. The temperature of the sensor material is indicated by its color (blue = "cold," yellow = "warm," red $=$ "hot").

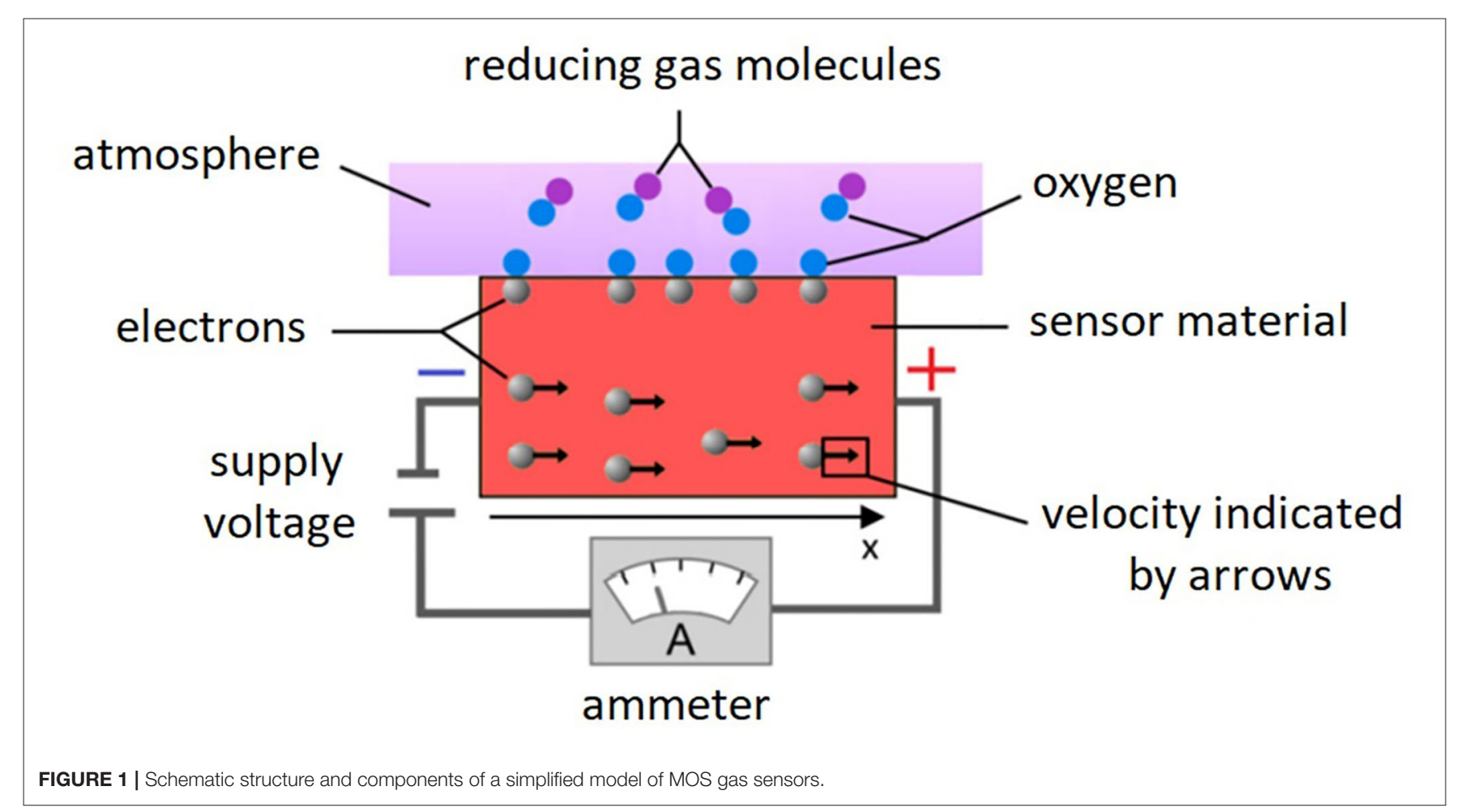



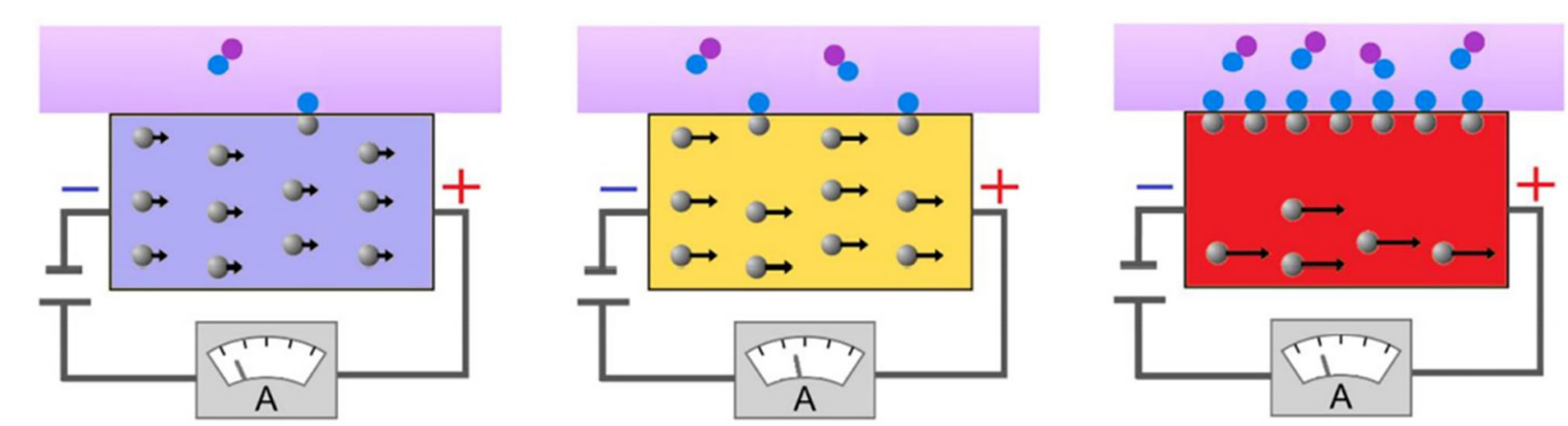

FIGURE 2 | Schematic representation of sensor behavior in an oxygen atmosphere with reducing gas at different temperature (blue = "cold," yellow = "warm," red = "hot"). On the one hand, the effective velocity of the free charge carriers increases with increasing temperature. On the other hand, fewer free charge carriers are available for charge transport.

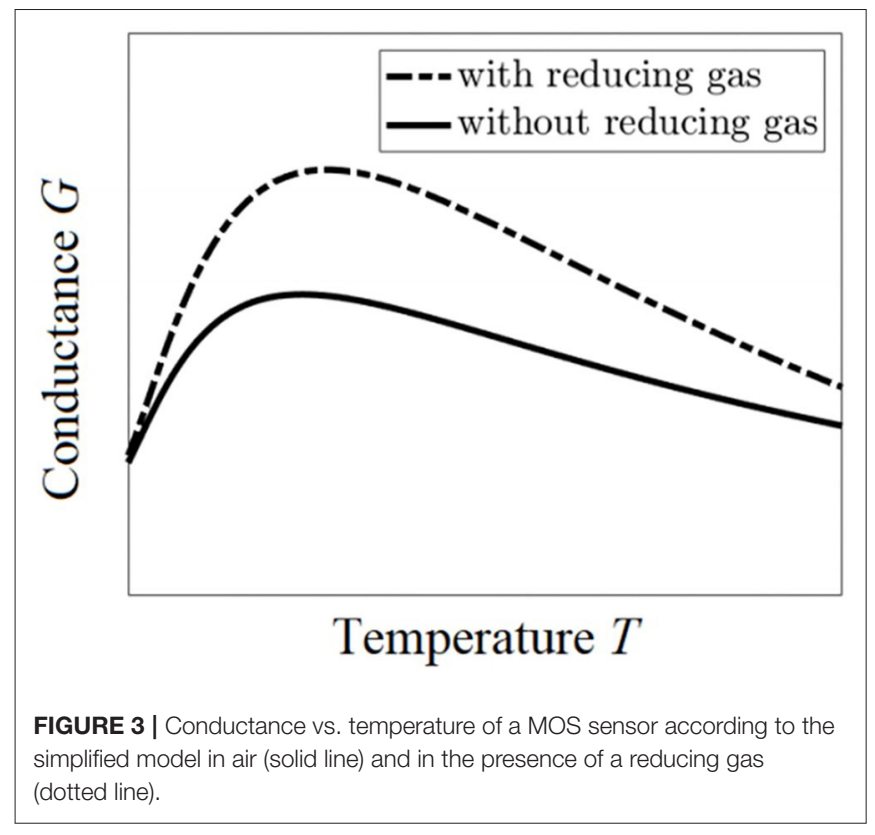

The simplified model describes the dependence of the electrical conductance on the sensor temperature by the superposition of two opposite effects. On the one hand, the sensor is interpreted by the image of a thermistor with negative temperature coefficient (NTC semiconductor) (Feteira, 2009). In these the electrical conductance increases with increasing temperature. This behavior is caused by an increase of the effective velocity of the free charge carriers within the material when an external voltage is applied. On the other hand, with increasing temperature, more oxygen molecules adsorb on the sensor surface and capture an electron, thus reducing the number of free charge carriers-the electrical conductance decreases, see Figure 2.

Due to the superposition of both effects, a maximum conductance is formed at medium temperatures, see Figure 3. Reducing gases from the atmosphere can react with the oxygen bound on the surface reducing the oxygen coverage of the surface. This releases formerly bound charge carriers, which increases the conductance. This change in conductance depends on the reaction rate of the gas with the bound oxygen, the gas concentration, and the sensor temperature. Different gases can therefore be identified and quantified by measuring the conductance at different operating temperatures and interpreting the resulting pattern.

\section{Carbon Dioxide $\left(\mathrm{CO}_{2}\right)$}

Carbon dioxide $\left(\mathrm{CO}_{2}\right)$ is a naturally occurring molecule in the Earth's atmosphere that is both colorless and odorless. It is known to students primarily due to the climate change and its importance as greenhouse gas. Furthermore, although $\mathrm{CO}_{2}$ is not a pollutant with respect to health effects it is frequently used as an indicator gas to determine IAQ due to its correlation to VOCs indoors (von Pettenkofer, 1858). Figure 4 shows the course of the $\mathrm{CO}_{2}$ and TVOC concentrations in a closed room over a period of $8 \mathrm{~h}$. After $\sim 380$ min, a window was opened, causing both concentrations to drop significantly.

\section{Sources, Limits, and Health Effects}

Indoors, humans are the mainsource of $\mathrm{CO}_{2}$, as exhaled air has a $\mathrm{CO}_{2}$ concentration of about $4 \%$ or 40,000 ppm (Lang, 2016). Already in the 19th century, Pettenkofer recognized that the $\mathrm{CO}_{2}$ concentration could be used as an indicator for IAQ, since it correlates with the TVOC concentration if humans are the primary source of VOCs. While $\mathrm{CO}_{2}$ itself has adverse health effects on humans, including concentration disorders, shortness of breath and confusion (Lahrz et al., 2008), but only at concentrations above 5,000 ppm, increased ventilation is recommended indoors already if the concentration is above $1,000 \mathrm{ppm}$, which is known as the Pettenkofer limit (von Pettenkofer, 1858).

\section{Simplified Sensor Principle}

There are different methods for detecting $\mathrm{CO}_{2}$ based on chemical and physical processes. The most common method to 


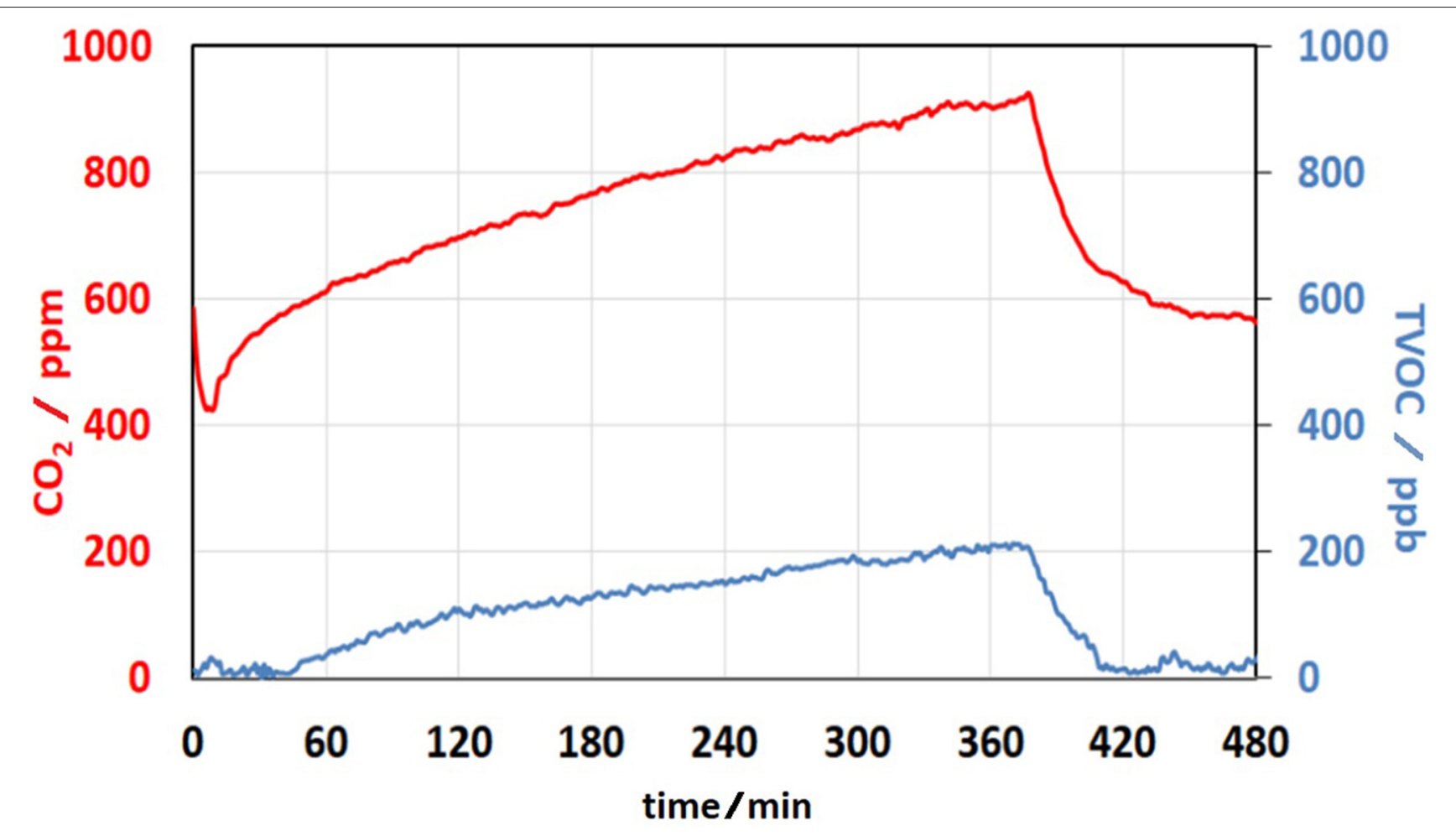

FIGURE 4 | Comparison of $\mathrm{CO}_{2}$ and TVOC concentrations in a closed indoor room over a period of $8 \mathrm{~h}$. The courses of the concentrations correlate. After about $380 \mathrm{~min}$, a window was opened and both concentrations dropped.

determine the $\mathrm{CO}_{2}$ concentration in air is based on infrared absorption. Infrared light with a wavelength of $\sim 4.3 \mu \mathrm{m}$ is absorbed by $\mathrm{CO}_{2}$ molecules as molecule oscillations are excited. The intensity of the light after passing through the medium is measured with a detector (Budzier and Gerlach, 2010). The intensity of the absorption depends on the concentration of the $\mathrm{CO}_{2}$ molecules and can be described by Lambert-Beer's law (Demtröder, 2012).

The wavelength-dependent absorption can be made clear to students by performing a simple experiment. For this purpose, the students are given cuvettes with different dilutions of red food dye as well as a red and a blue LED. The light from the blue LED is absorbed when passing through the red liquid, whereas the light from the red LED is transmitted almost undisturbed. The intensity of the transmitted blue laser light decreases with increasing dye concentration following Lambert-Beer's law, see Figure 5. The molecules of the red food dye symbolize $\mathrm{CO}_{2}$ molecules. This experiment illustrates the selective absorption of infrared light by $\mathrm{CO}_{2}$ molecules.

\section{Particulate Matter (PM)}

Particulate matter (PM) refers to solid or liquid particles in the air with an aerodynamic diameter smaller than $10 \mu \mathrm{m}$. They are often divided into the subgroups $\mathrm{PM}_{10}, \mathrm{PM}_{2.5}$, and $\mathrm{PM}_{1}$, where the index indicates the maximum aerodynamic diameter in $\mu \mathrm{m}$.

\section{Sources, Limits, and Health Effects}

There are both natural sources of PM, such as forest fires, pollen, and soil erosion, as well as anthropogenic sources, such as power plants, motor vehicles, and incinerators. In cities, road traffic, especially diesel exhaust (soot), brake and tire abrasion, is the main source of PM (Stieß, 2009).

If $\mathrm{PM}$ enters the respiratory tract, it can cause damage. The depth of penetration depends on their size, with smaller particles being able to penetrate deeper into the human body and therefore being potentially more harmful. There is no threshold concentration below which no health damage occurs. Therefore, PM exposure should always be kept as low as possible (World Health Organization, 2013a; Umweltbundesamt, 2017). Since 2005, limit values for the various PM fractions have been established within the EU. Thus, the daily mean concentration of $\mathrm{PM}_{10}$ must not exceed the limit value of $50 \mu \mathrm{g} / \mathrm{m}^{3}$ more than 35 times per year. In addition, the annual mean value must not exceed $40 \mu \mathrm{g} / \mathrm{m}^{3}$. The limit value for the average $\mathrm{PM}_{2.5}$ concentration distributed over the year is $25 \mu \mathrm{g} / \mathrm{m}^{3}$ (World Health Organization, 2013a).

PM can accumulate heavy metals and polycyclic aromatic hydrocarbons on their surface, which are carcinogenic according to WHO and thus belong to Group 1 carcinogens (World Health Organization, 2013b). Diseases resulting from increased exposure to PM include deterioration of lung function, asthma, exacerbations in chronic obstructive pulmonary disease COPD, and cardiovascular disease (Schweisfurth, 2015). 

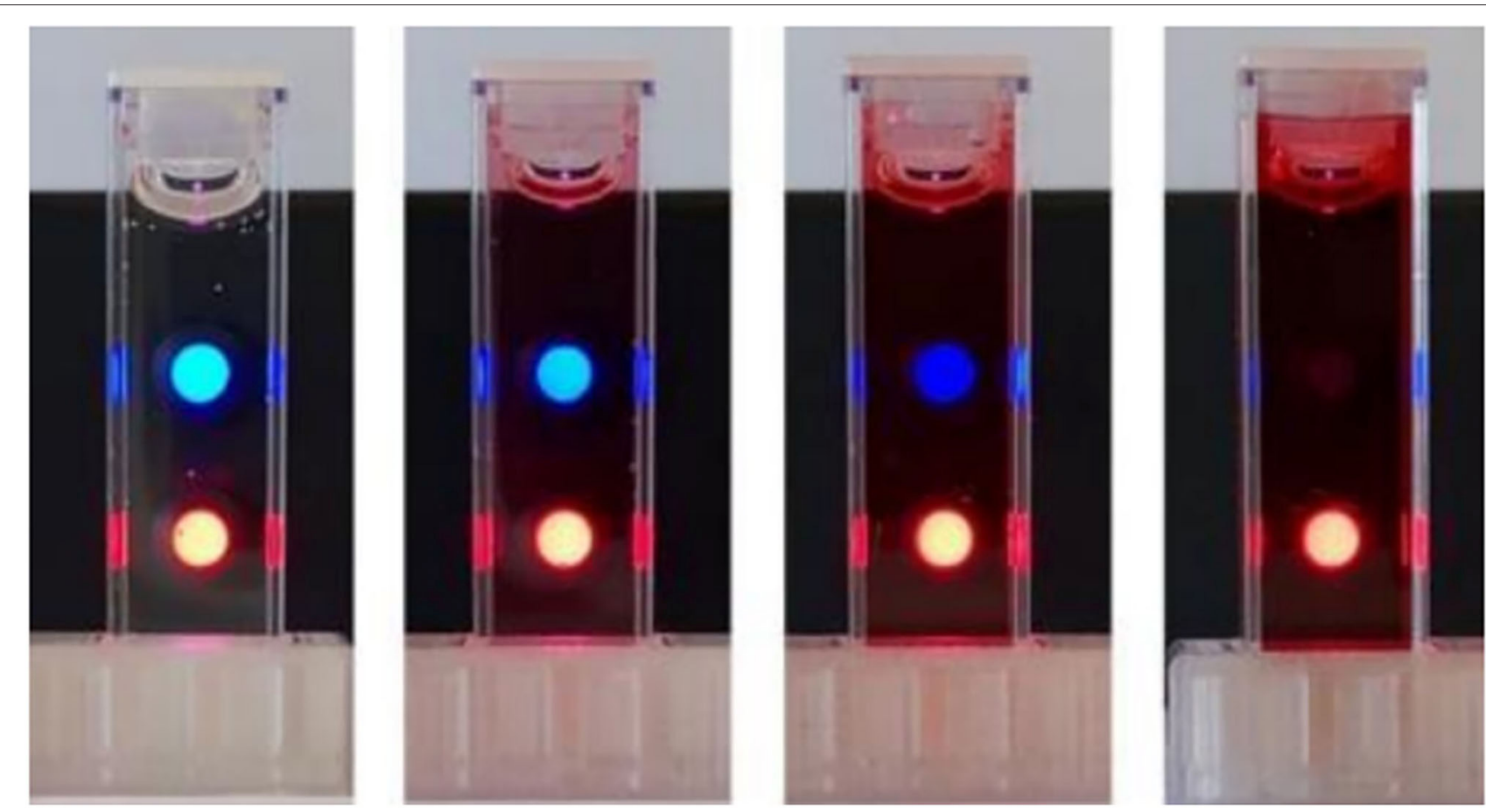

FIGURE 5 | Transmission of blue and red LEDs through water colored with red dye to demonstrate the function principle of wavelength dependent absorbance. Dye concentration can be determined from the relative intensities of both LEDs.

\section{Simplified Sensor Principle}

There are several ways to measure PM. These include radiometric, cumulative, gravimetric, or non-optical methods based on the field disturbance principle. In addition, a distinction is made between continuous and discontinuous measurement methods, in which the analysis is performed either directly on site or in the laboratory. The most common particle measurement method in modern low-cost PM sensors is based on continuous optical methods using light scattering (Stieß, 2009). Based on the scattering intensity and pattern, conclusions can be drawn about the number of particles and their size distribution.

To familiarize students with the basic principle of a PM sensor based on light scattering, a simple experiment is suitable in which a laser pointer is used to shine through suspensions of different concentrations of silicate beads in water, see Figure 6. With the bare eye, it is difficult to observe any difference between the three samples. Only with the laser pointer shining through the cuvettes the densities of the different suspensions become visible as a result of light scattering.

\section{AUTHENTIC LEARNING EXPERIMENTS}

In addition to teaching declarative and conceptual knowledge about pollutants and sensor principles, experiments with these sensors can enable authentic learning scenarios by having students perform exemplary measurements. These experiments should be related to everyday life so that findings from these measurements can be directly transferred to the students' personal environment. On this basis, various (introductory) experiments with VOC, $\mathrm{CO}_{2}$ and particulate matter sensors are presented below, giving students their first experience in using sensors and interpreting the results. Critical assessment of the measurement results helps students draw personal conclusions and thus teaches procedural knowledge. Each experiment has a different focus and shows the versatility of sensors. On this basis, students are encouraged to develop their own research questions according to their personal interests.

The experimental basis is a printed circuit board (PCB) equipped with a VOC sensor (SGP30; Sensirion, 2020a), an NDIR-CO 2 sensor (SCD30; Sensirion, 2020b) and a PM sensor (SPS30; Sensirion, 2020c, all from Sensirion, CH), see Figure 7. The sensors are controlled and read out via an $\mathrm{I}^{2} \mathrm{C}$ interface with an ESP8266 NodeMCU v3 microcontroller (Lolin, 2015). Programming is done using the Arduino IDE with freely available libraries from Adafruit (2020a,b), Sensirion (2020d). A micro USB cable is used to transfer the data to a PC with measurement software and graphical user interface (GUI) developed as part of the project.

\section{Nose vs. Sensor}

In the first experiment, the students test how reliable their nose is. For this purpose, they are given five different dilutions of ethanol in water. At the beginning of the experiment, the samples are not labeled and the students are asked to sort them according to their ethanol concentration by smelling them. For 

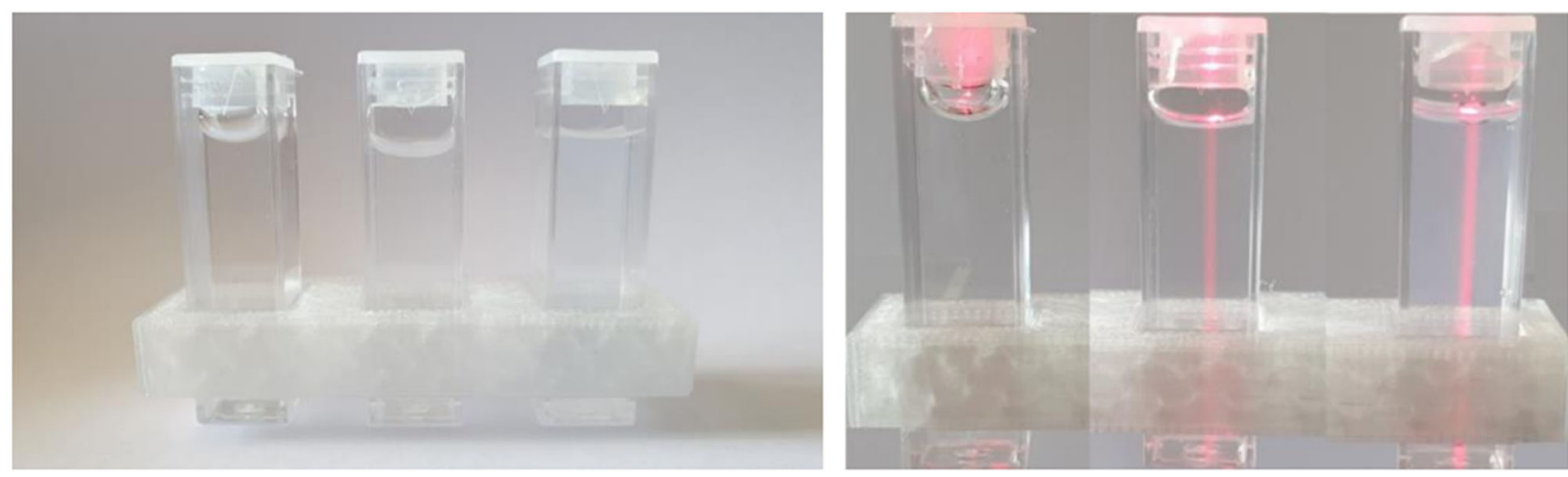

FIGURE 6 | Experiment demonstrating the principle of a PM sensor based on light scattering. Left: Three cuvettes with different suspensions consisting of water and different concentrations of silicate beads. Right: Demonstration of the principle of light scattering. The higher the concentration of the silicate beads, the more the light is scattered.

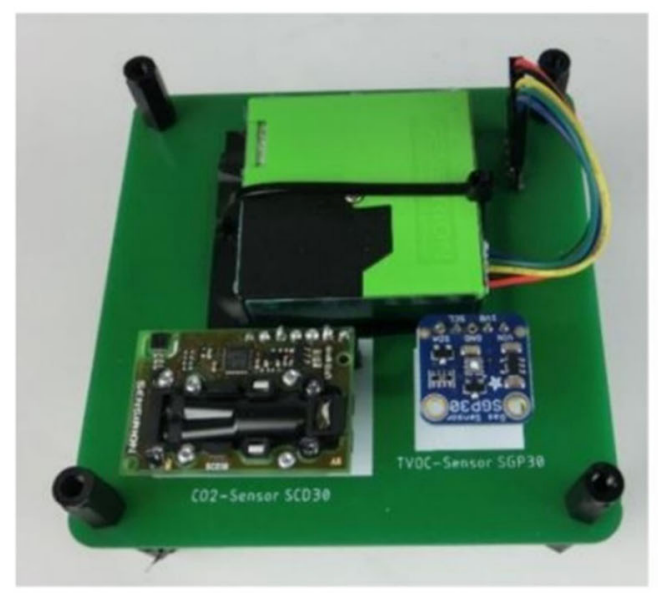

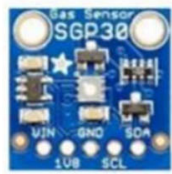

SGP30

- TVOC

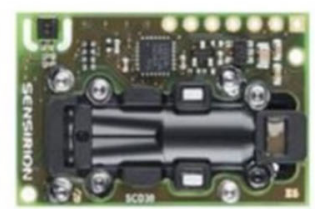

SCD30

$-\mathrm{CO}_{2}$

- Temperature

- Relative Humidity

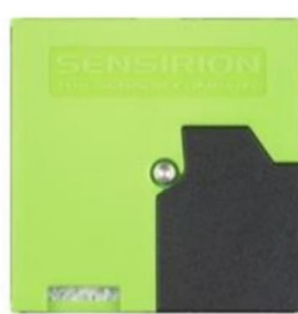

SPS 30

- Particulate Matter

FIGURE 7 | Sensor board for environmental measurements containing a MOS gas sensor for VOC measurements (SGP30), an CO 2 sensor based on IR absorption (SCD30) and a PM sensor based on light scattering (SPS30, all from Sensirion, CH).

the different dilutions, care was taken to ensure that the three lowest concentrations are below the human odor threshold, so students generally cannot distinguish between them. Once the students have submitted their guess, the samples are measured with the VOC sensor. The diluted samples are placed in a container with the sensor board on top. After a few seconds, the VOC sensor can reliably sort the samples based on their ethanol concentration, see Figure 8.

This experiment creates awareness of the need for objective measurements of air pollutants since certain gases are not or at best only faintly perceived by the nose, even at high concentrations.

\section{VOC Emissions From Everyday Products}

In the second experiment with the VOC sensor, the students examine the VOC emissions of various everyday objects such as paints, felt-tip markers, adhesives, and floor coverings. In each case, they compare a conventional product with one that is explicitly labeled as "low-emission" and carries an ecolabel, e.g., the "Blue Angel." Students assign points for odor intensity from 0 ("imperceptible") to 6 ("very strong") based on the guideline "VDI 3882 Part 1: Olfactometry Determination of Odor Intensity (1992)" (Verein deutscher Ingenieure e, 1992). Subsequently, the samples are measured with the VOC sensor and points are assigned based on its reading. For all examples used in the experiment, there are low-emission alternatives to the conventional products. Since the VOC sensor only indicates the total VOC value, the samples were additionally analyzed using gas chromatography-mass spectrometry (GCMS) to determine the exact components and relative proportions of the total emission, see Figure 9. In this way, the students are sensitized to the pollutant content of everyday products and can draw their own personal conclusions about their future use of certain products. 

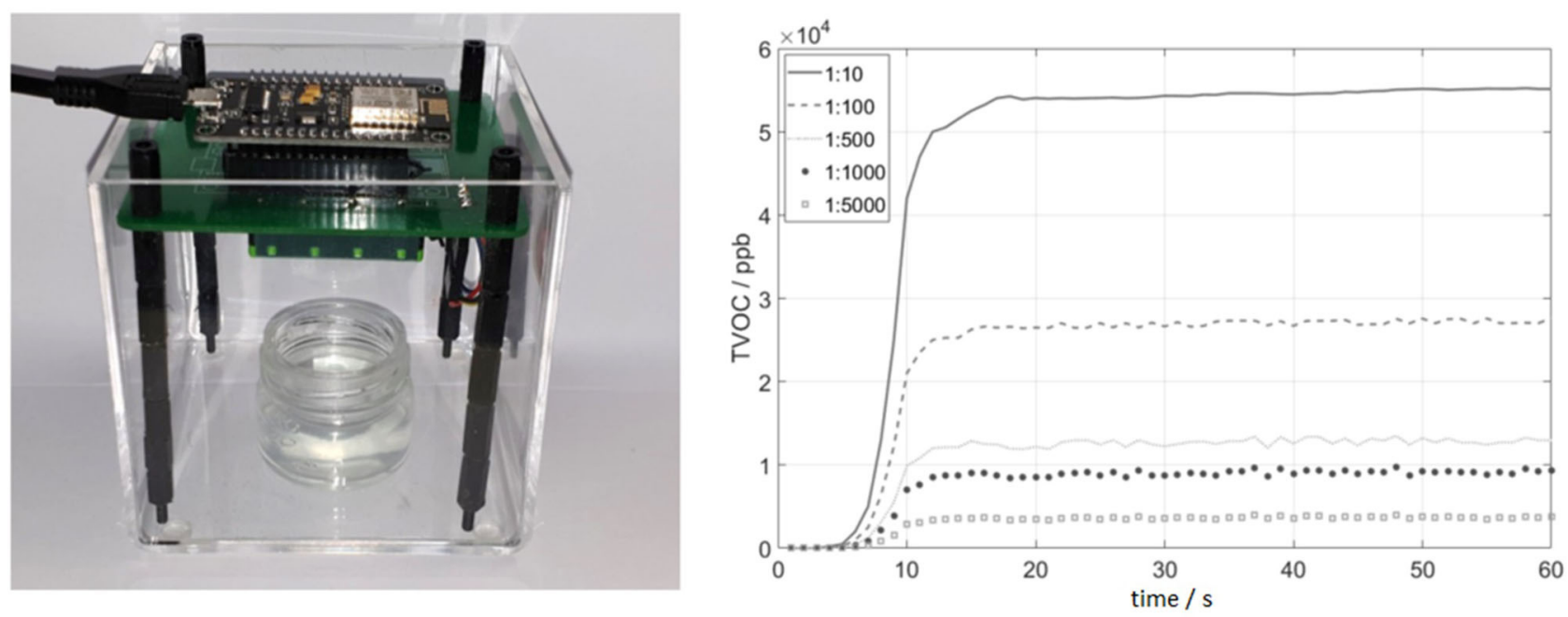

FIGURE 8 | Left: Experimental setup to quantify VOC emissions from samples. Right: Sensor reaction.

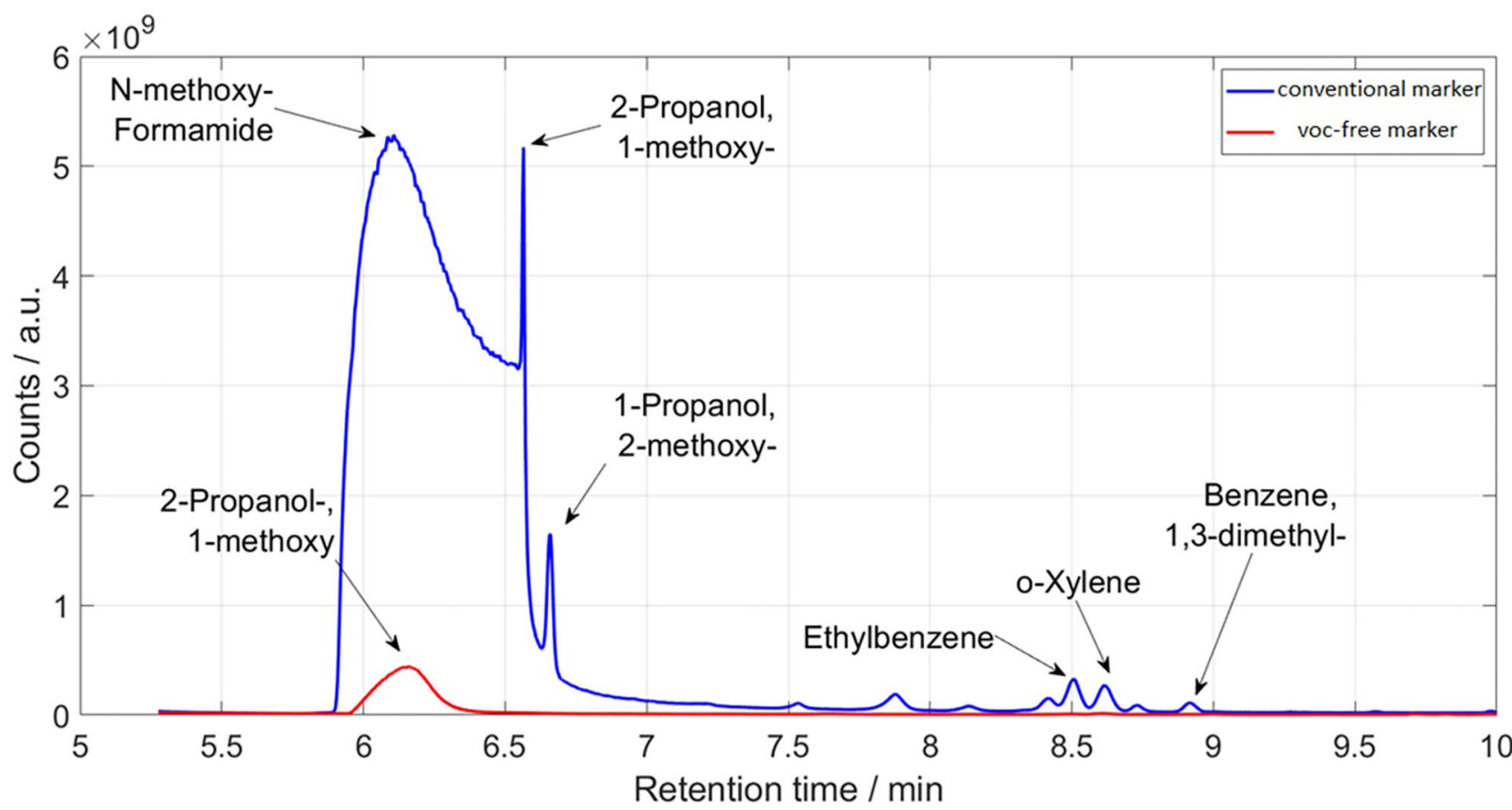

FIGURE 9 | GC-MS reference measurement of the head-space composition of conventional and VOC-free markers.

\section{Walk-In Measurement \\ Chamber-Simulated Interior}

To demonstrate the degradation of IAQ in case of insufficient ventilation, a walk-in measurement chamber was constructed in which the VOC and $\mathrm{CO}_{2}$ concentration is measured and visualized in real time. Furthermore, the chamber is equipped with fans that can be switched on if desired. In this experiment, students first sit in the closed measurement chamber for about
$3 \mathrm{~min}$. Then they are encouraged to exercise for $3 \mathrm{~min}$, e.g., with squats. Finally, the door of the measurement chamber is opened. The experiment is then repeated with the fans turned on, providing continuous circulation of the air. Example results of this measurement are shown in Figure 10. Both $\mathrm{CO}_{2}$ and TVOC concentrations increase significantly when the fans are turned off. However, the increase is much smaller with the fans turned on. This experiment has two goals. First, to show 
the students that $\mathrm{CO}_{2}$ and TVOC are correlated if humans are the primary source of VOCs. On the other hand, students will be made aware of the need for regular ventilation, as both $\mathrm{CO}_{2}$ and TVOC concentrations can be kept low. The fact that students themselves are part of this experiment provides a special authenticity. Procedural knowledge is imparted in the form of instructions for regular ventilation.

\section{PM Emission}

In this experiment, the students investigate the PM emission of school chalk when writing on and wiping off a blackboard. For this purpose, they are given a low-emission chalk pen (chalk A) and a piece of commercially available school chalk (chalk B). They are also provided with a blackboard, a wet and a dry sponge, see Figure 11, left.

The measurement procedure consists of 4 phases, each lasting $\sim 30 \mathrm{~s}:$
1) Writing on the board

2) Cleaning the board with a dry sponge

3) Writing on the board again

4) Cleaning the board with a wet sponge.

The experiment is performed for both types of chalk. Both sponges are cleaned after one pass. It shows that the chalk pen produces significantly less PM than the conventional school chalk. The test setup and typical measurement results are shown in Figure 11, right. Shortly after starting to write on the blackboard with the conventional chalk, the $\mathrm{PM}_{2.5}$ concentration near the blackboard increases to $\sim 50 \mu \mathrm{g} / \mathrm{m}^{3}$, which already represents an exceedance of the average limit value of $25 \mu \mathrm{g} / \mathrm{m}^{3}$. In contrast, the PM concentration does not change when writing with the low-emission chalk. As soon as the blackboard is wiped with a dry sponge, large quantities of PM are released, which is evident from the hugely increased measured values. In the second writing phase, the PM concentration drops again to a
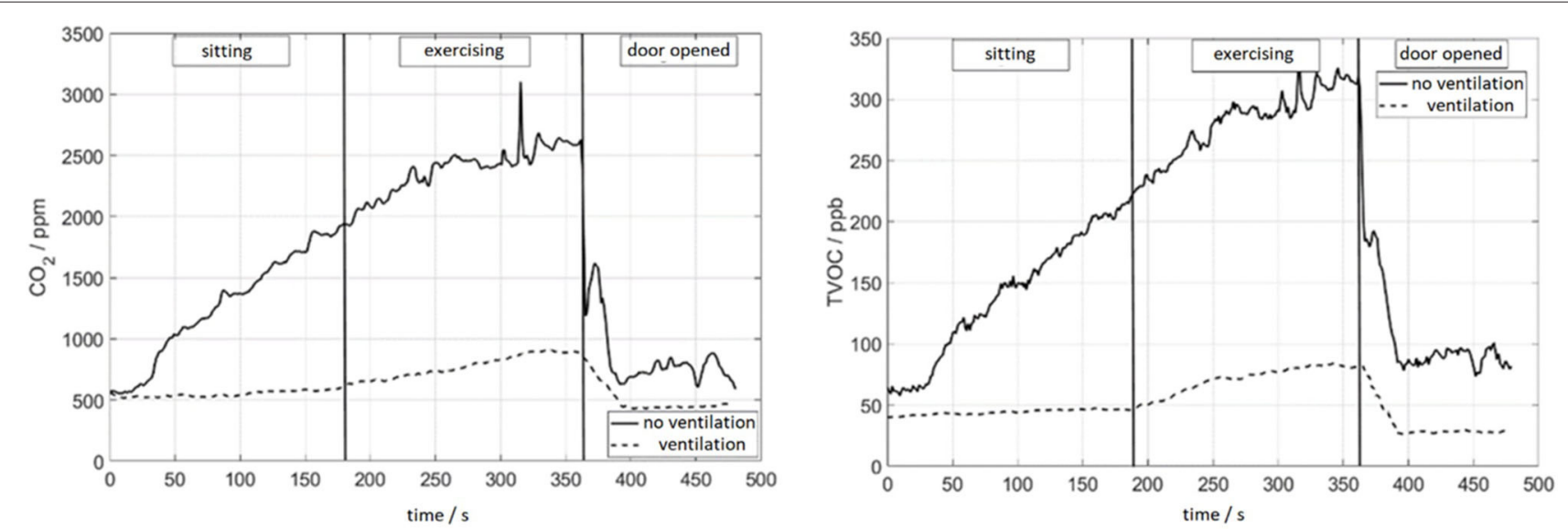

FIGURE 10 | Exemplary results of the experiment with a simulated interior. $\mathrm{CO}_{2}$ (left) and TVOC (right) concentrations inside the measuring chamber over time. Solid lines indicate the chamber without ventilation, dotted lines with ventilation.
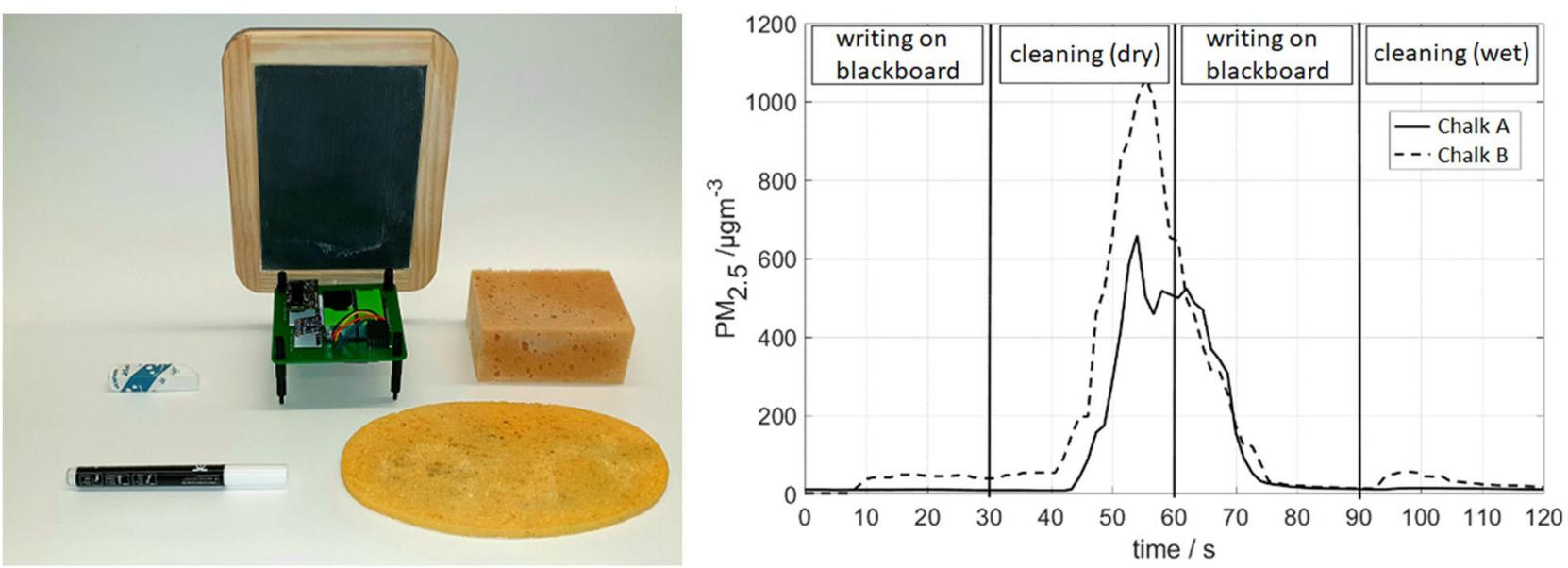

FIGURE 11 | Left: Experimental setup of the PM emission experiment. Right: Exemplary results of the PM emission of different chalk types (chalk A: low-emission chalk pen, chalk B: commercially available school chalk). 
normal level. In the final wiping phase with a wet sponge, the $\mathrm{PM}$ concentration increases only minimally for chalk $\mathrm{B}$, while no increase is detected with chalk $\mathrm{A}$.

To realistically assess expected PM pollution in a classroom, the students are asked to critically question and interpret the measured values in a final task. For instance, although the PM load near the blackboard is increased for a short time, it can be assumed that only a small part of it is distributed in the room air. Regular ventilation can help keep the overall PM concentration below the limit value. Furthermore, the use of a low-emission chalk pen would be a suitable alternative to regular chalk.

\section{Development of Own Experiments-Example: $\mathrm{CO}_{2}$ Traffic Light in Classrooms}

Based on the knowledge gained by the students in the various experiments about gas sensors and air quality determination, they are encouraged to develop their own questions. They are supported by scientists from the Laboratory for Measurement Technology at Saarland University in Saarbruecken, Germany, as well as teachers and the Student Research Center in Saarlouis, Germany.

Due to the current corona pandemic and the requirement to ventilate classrooms regularly in order to keep the potential viral load in the air as low as possible, two students of the Albert
Schweitzer Gymnasium in Dillingen/Saar, Germany, developed the idea of a $\mathrm{CO}_{2}$ traffic light, which should be installed in all classrooms. Their idea was that the measured $\mathrm{CO}_{2}$ value of the indoor air can also be used as a "corona indicator" as both $\mathrm{CO}_{2}$ and viral load are resulting from exhaled air. The objective measurement of the air quality can ensure on the one hand that the classroom is sufficiently ventilated by opening the windows and on the other hand that the classroom does not cool down unnecessarily due to too frequent or long ventilation.

For this purpose, they developed a circuit board integrating a $\mathrm{CO}_{2}$ sensor (SCD30) and a VOC sensor (SGP30) at the Student Research Center in Saarlouis, Germany, see Figure 12 left. Also integrated on the board are three LEDs similar to a traffic light as well as a buzzer generating an acoustic signal when a relevant threshold limit of the $\mathrm{CO}_{2}$ concentration is reached. The sensors are controlled with the internet-enabled microcontroller ESP32 D1 NodeMCU (AZ-Delivery, 2020). This sends the measurement data in anonymized form to an online database. In addition, the students defined the limits and recommended actions according to Table 1.

To protect the circuit board and sensors from external influences, a 3D printed housing was also designed and realized, see Figure 12, right.

After testing the first prototype, a total of $60 \mathrm{CO}_{2}$ traffic lights have now been built by students of the Albert Schweitzer Gymnasium and installed in the school. The installation was
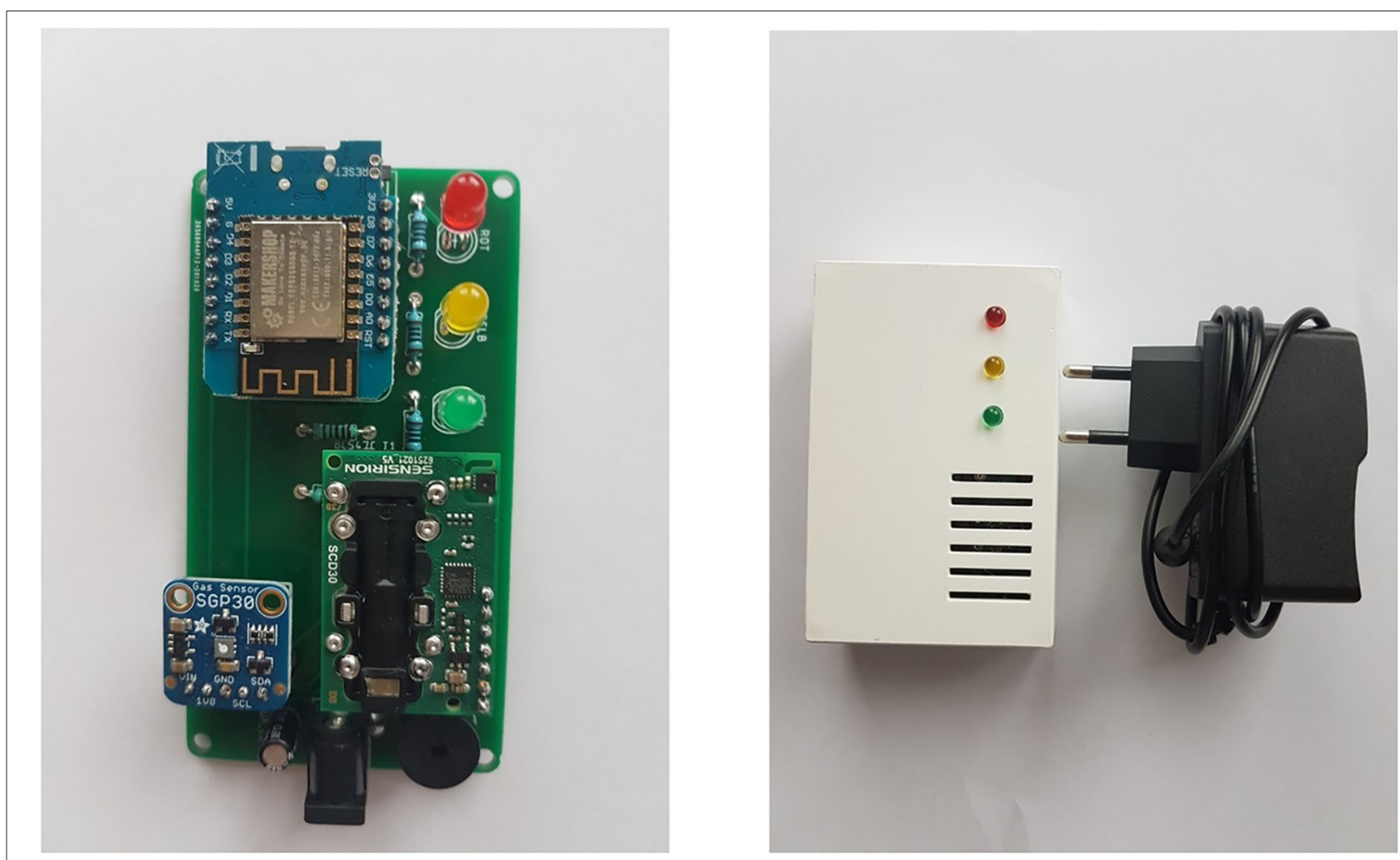

FIGURE 12 | Left: $\mathrm{CO}_{2}$ traffic light consisting of internet-enabled microcontroller ESP32, $\mathrm{CO}_{2}$ sensor SCD30, TVOC sensor SGP30 as well as a buzzer and 3 LEDs for visualization of the current $\mathrm{CO}_{2}$ concentration. Right: 3D-printed housing. 
TABLE 1 | Defined limits, indicators, and recommendations for the $\mathrm{CO}_{2}$ traffic light.

\begin{tabular}{lll}
\hline $\mathbf{C O}_{\mathbf{2}}$ concentration $\mathbf{c / p p m}$ & Indicator & Recommendation \\
\hline $0<\mathrm{C}<750$ & Green LED & No ventilation required \\
$750<\mathrm{C}<1.000$ & Yellow LED & Ventilation recommended \\
$\mathrm{C}>1.000$ & Red LED and & Ventilation required \\
& acoustic & \\
& signal & \\
&
\end{tabular}

accompanied scientifically by Saarland University. In the future, the measured sensor data will provide insights into ventilation behavior and air quality in classrooms. This will also allow comparing the situation in different rooms as well as different ventilation strategies, i.e., opening the windows for 5 min every 20 min vs. $\mathrm{CO}_{2}$-based ventilation.

\section{CONCLUSION AND OUTLOOK}

According to today's understanding, environmental awareness is composed of various factors and includes not only environmental knowledge but also aspects of environmental attitude and environmental behavior. While providing facts about environmental issues is a necessary first step in improving environmental awareness, it is not sufficient on its own to achieve sustainable change. The underlying principle of inert knowledge states that sustainable improvement can only be achieved if knowledge is also taught in an application-oriented manner and in authentic learning scenarios. Furthermore, environmental knowledge can also be divided into declarative, conceptual, and procedural knowledge. Related to the topic of air quality, declarative and conceptual knowledge include knowledge about the existence of pollutants, limit values, health hazards as well as sources and underlying measurement principles. In addition, procedural knowledge must be taught in the form of action knowledge.

An effective way to teach environmental knowledge about air quality in an authentic, situated, and application-oriented way is to conduct experiments with air quality sensors. The experiments presented in this contribution address MOS gas sensors, $\mathrm{CO}_{2}$ sensors based on infrared absorption and PM sensors based in light scattering. They combine both the transfer of knowledge about pollutants and knowledge about measurement principles. By independently measuring and interpreting measurement results in authentic and everyday learning scenarios, students gain knowledge that has a direct impact on their personal life situation. For example, students learn that gas sensors are more reliable than their nose or that regular ventilation is essential to maintain good indoor air quality. In addition, an awareness of the pollutant emissions of everyday products is created and alternatives are shown.

These experiments serve as a first introduction to working with air quality sensors and encourage students to develop their own questions. Students can decide for themselves which topic they want to work on, which guarantees motivation. Furthermore, the scientific supervision gives them an insight into scientific work. For example, two students were able to codevelop a $\mathrm{CO}_{2}$ traffic light with the help of scientific supervisors, which will be used at a school in the future and, in addition to providing a warning of poor air quality, will also provide new insights into ventilation behavior. Further student environmental studies developed in the context of this project were described in previous publications (Schütze et al., 2018; Höfner and Schütze, 2019; Höfner et al., 2019, 2020). These examples include the study of the air composition in beehives or the development of a pollutant map. All materials for replicating the experiments are publicly available and can be downloaded in the "Downloads" -section of the project website. ${ }^{1}$

\section{DATA AVAILABILITY STATEMENT}

The raw data supporting the conclusions of this article will be made available by the authors, without undue reservation.

\section{AUTHOR CONTRIBUTIONS}

All authors listed have made a substantial, direct and intellectual contribution to the work, and approved it for publication.

\section{FUNDING}

The work was part of the SUSmobil project, funded by the Deutsche Bundesstiftung Umwelt (DBU; AZ: 33704/01) within the framework of the funding line Education for Sustainable Development (German: Bildung für nachhaltige Entwicklung).

\section{ACKNOWLEDGMENTS}

Special thanks go to Benjamin Brück, head of the Student Research Center Saarlouis, Germany, and Wolfgang Thewes, teacher at the Albert Schweitzer Gymnasium Dillingen, Germany.

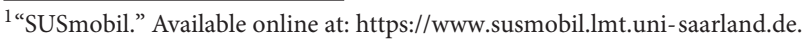

\section{REFERENCES}

Adafruit (2020a). Adafruit_Sensor_Master Library. Available online at: https:// github.com/adafruit/Adafruit_Sensor (accessed March 12, 2021).

Adafruit (2020b). SGP30_Master. Available online at: https://github.com/adafruit/ Adafruit_SGP30 (accessed March 12, 2021).

Anderson, J. R. (1996). Kognitive Psychologie. Heidelberg/Berlin/Oxford: Spektrum Akademischer Verlag.
AZ-Delivery (2020). ESP 32 D1 NodeMCU Datasheet. Available online at: https://cdn.shopify.com/s/files/1/1509/1638/files/D1_Mini_ESP32_ Datenblatt_AZ-Delivery_Vertriebs_GmbH.pdf?v=1604068666 (accessed March 12, 2021).

Bahr, M. (2013). Umweltbildung. Potsdam: Schriftenreihen/Potsdamer Geographische Praxis, 71-78.

Budzier, H., and Gerlach, G. (2010). Thermische Infrarotsensoren. Weinheim: Wiley VCH. 
Bundesanstalt für Arbeitsschutz und Arbeitsmedizin (2006). Arbeitsplatzgrenzwerte (TRGS 900). Bekanntmachung des BMAS. GMBI 55:1094.

Chen, X., Li, F., Liu, C., Yang, C., Zhang, J., and Peng, C. (2017). Monitoring human health risk assessment and optimized management for typical pollutants in indoor air from random families of universities staff, Wuhan City, China. Sustainability 9:1115. doi: 10.3390/su9071115

de Haan, G., and Kuckartz, U. (1996). Umweltbewusstsein: Denken und Handeln in Umweltkrisen. Opladen: VS Verlag für Sozialwissenschaften. doi: 10.1007/978-3-322-83265-8

de Witt, C., and Czerwionka, T. (2012). Mediendidaktik. Bielefeld: W. Bertelsmann Verlag.

Demtröder, W. (2012). Experimentalphysik 2-Elektrizität und Optik. Kaiserslautern: Springer-Verlag.

Drude, P. (1900). Zur Elektronentheorie der Metalle. Annalen der Physik. 306, 566-613. doi: $10.1002 /$ andp. 19003060312

European Environment Agency (2019). EEA Report No 10/2019. Copenhagen. doi: $10.1016 / S 0306-3747(19) 30103-4$

Feteira, A. (2009). Negative Temperature Coefficient Resistance (NTCR) ceramic thermistors: an industrial perspective. J. Am. Cer. Soc. 92, 967-983. doi: 10.1111/j.1551-2916.2009.02990.x

Guenther, A., Hewitt, C.N., Erickson, D., Fall, R., Geron, C., Graedel, T., et al. (1995). A global model of natural volatile organic compound emission. J. Geophys. Res. 100, 8873-8892. doi: 10.1029/94JD02950

Höfner, S, Hirth, M., Kuhn, J., Brueck, B., and Schütze, A. (2020). "Citizen Science for students: fundamentals of gas sensing and realization of environmental studies," in IMCS2020-The 18th International Meeting on Chemical Sensors (Montréal), 10-14. doi: 10.1149/MA2020-01292241mtgabs

Höfner, S., Hirth, M., Brück, B., Kuhn, J., and Schütze, A. (2021). Modeling the function principle of metal oxide semiconductor gas sensors for high school students. Int. J. Online Biomed. Eng. 17, 5-25. doi: 10.3991/ijoe.v17i03.19213

Höfner, S., and Schütze, A. (2019). Umweltstudien mit Smartphone für Schüler*innen am Beispiel der Untersuchung der Luft in Bienenstöcken. 14. Dresden: Dresdner Sensor-Symposium, 2-4. doi: 10.5162/14dss2019/P1.12

Höfner, S., Schütze, A., Brück, B., Hirth, M., and Kuhn, J. (2019). Citizen Science für Schüler*innen: Durchführung von Umweltstudien mit Smartphone und mobiler Messtechnik. 20. Nuremberg: GMA/ITG Fachtagung Sensoren und Messsysteme, 25-26. doi: 10.5162/sensoren2019/6.1.5

Lahrz, T., Bischof, W., Sakunski, H., Baudisch, C., Fromme, H., Grams, H., et al. (2008). Gesundheitliche Bewertung von Kohlendioxid in der Innenraumluft. Bekanntmachung des Umweltbundesamtes. Springer Medizin Verlag. 51, 1358-1369. doi: 10.1007/s00103-008-0707-2

Lang, H. (2016). Beatmung für Einsteiger. Theorie und Praxis für die Gesundheits- und Krankenpflege. Hamburg: Springer-Verlag. doi: 10.1007/978-3-662-45989-8

Lolin (2015). ESP8266 NodeMCU v3. Available online at: https://components101. com/asset/sites/default/files/component_datasheet/ESP8266-NodeMCUDatasheet.pdf (accessed March 12, 2021).

Milton, B., Cleveland, E., and Bennet-Gates, D. (1995). Changing perceptions of nature, self, and others: a report on a park/school program. J. Environ. Educ. 26, 32-39. doi: 10.1080/00958964.1995.9941443

Renkl, A., Mandl, H., and Gruber, H. (1996). Inert knowledge: analyses and remedies, educational Psychologist, 31, 115-121. doi: 10.1207/s15326985ep3102_3

Rode, H. (2001). Umwelterziehung in der Schule. Zwischen Anspruch und Wirklichkeit. Wiesbaden: Leske+Budrich Verlag. doi: 10.1007/978-3-663-11677-6

Sagunski, H., and Heinzow, B. (2003). Bundesgesundheitsblattgesundheitsforschung - gesundheitsschutz. Umweltbundesamt 46, 346-352. doi: 10.1007/s00103-003-0584-7

Schneider, M. (2006). Konzeptuelles und prozedurales Wissen als latente Variablen: Ihre Interaktion beim Lernen mit Dezimalbrüchen. [dissertation]. [Berlin]: Technische Universität Berlin.
Schütze, A., Höfner, S., Brück, B., Hirth, M., and Kuhn, J. (2018). “Citizen science with smart gas sensors: air quality assessment and environmental studies by students," in Proceedings IMCS 2018-17th International Meeting on Chemical Sensors (Vienna). doi: 10.5162/IMCS2018/ME.5

Schweisfurth, H. (2015). Gesundheitsschäden durch Feinstaub. Cottbus: Pulmologisches Forschungsinstitut.

Sensirion (2020a). Datasheet SGP30. Available online at: https://www.sensirion. com/fileadmin/user_upload/customers/sensirion/Dokumente/9_Gas_ Sensors/Datasheets/Sensirion_Gas_Sensors_Datasheet_SGP30.pdf (accessed March 12, 2021).

Sensirion (2020b). Datasheet SCD30. Available online at: https://www.sensirion. com/fileadmin/user_upload/customers/sensirion/Dokumente/9.5_CO2/ Sensirion_CO2_Sensors_SCD30_Datasheet.pdf (accessed March 12, 2021).

Sensirion (2020c). Datasheet SPS30. Available online at: https://www. sensirion.com/fileadmin/user_upload/customers/sensirion/Dokumente/9. 6_Particulate_Matter/Datasheets/Sensirion_PM_Sensors_Datasheet_SPS30. pdf (accessed March 12, 2021).

Sensirion (2020d). SCD30_Master. Available online at: https://github.com/ Sensirion/embedded-scd/blob/master/scd30/scd30.h (accessed March $12,2021)$.

Stieß, M. (2009). Mechanische Verfahrenstechnik-Partikeltechnologie 1. Berlin/Heidelberg: Springer-Verlag.

Szagun, G., Mesenholl, E., and Jelen, M. (1994). Umweltbewusstsein bei Jugendlichen. Emotionale, handlungsbezogene und ethische Aspekte. Frankfurt: Lang Verlag.

Umweltbundesamt (2017). Warum ist Feinstaub schädlich für den Menschen? http://www.umweltbundesamt.de/service/uba-fragen/ warum-ist-feinstaub-schaedlich-fuer-den-menschen (accessed March 12, 2021).

US Environmental Protection Agency (1991). Sick Building Syndrome. Indoor Air Facts. 4. Available online at: https://www.epa.gov/sites/production/files/201408/documents/sick_building_factsheet.pdf (accessed March 12, 2021).

Verein deutscher Ingenieure e,V. (1992). Olfactometry; Determination of Odour Intensity. Düsseldorf: VDI/DINKommission Reinhaltung der Luft (KRdL) Normenausschuss.

von Pettenkofer, M. (1858). Über Luftwechsel in Wohngebäuden. München: J.G. Cotta Verlag.

Wolkoff, P., Clausen, P.A., Jensen, B., Nielsen, G., and Wilkins, C. (2004). Are we measuring the relevant indoor pollutants? Indoor Air. 7, 92-106. doi: 10.1111/j.1600-0668.1997.t01-2-00003.x

World Health Organization (2000). Occupational and Environmental Health Team. Guidelines for Air Quality. Geneva.

World Health Organization (2010). WHO Guidelines for Indoor Air Quality: Selected Pollutants. Available online at: https://www.euro.who.int/_data/ assets/pdf_file/0009/128169/e94535.pdf (accessed March 12, 2021).

World Health Organization (2013a). Health Effects of Particulate Matter. Available online at: https://www.euro.who.int/_data/assets/pdf_file/0006/ 189051/Health-effects- of-particulate-matter-final-Eng.pdf?ua=1 (accessed March 12, 2021).

World Health Organization (2013b). Press Release 221, 2013. Available online at: http://www.iarc.fr/en/media-centre/pr/2013/pdfs/pr221_E.pdf (accessed March 12, 2021).

Conflict of Interest: The authors declare that the research was conducted in the absence of any commercial or financial relationships that could be construed as a potential conflict of interest.

Copyright $\odot 2021$ Höfner and Schütze. This is an open-access article distributed under the terms of the Creative Commons Attribution License (CC BY). The use, distribution or reproduction in other forums is permitted, provided the original author(s) and the copyright owner(s) are credited and that the original publication in this journal is cited, in accordance with accepted academic practice. No use, distribution or reproduction is permitted which does not comply with these terms. 